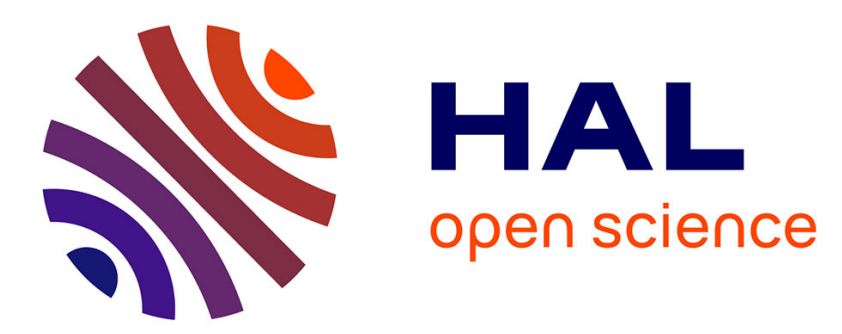

\title{
Numerical and experimental studies of the generation of ultrasound by laser
}

\author{
M. Dubois, F. Enguehard, L. Bertrand, M. Choquet, J.-P. Monchalin
}

\section{To cite this version:}

M. Dubois, F. Enguehard, L. Bertrand, M. Choquet, J.-P. Monchalin. Numerical and experimental studies of the generation of ultrasound by laser. Journal de Physique IV Proceedings, 1994, 04 (C7), pp.C7-689-C7-692. 10.1051/jp4:19947161 . jpa-00253221

\section{HAL Id: jpa-00253221 https://hal.science/jpa-00253221}

Submitted on 1 Jan 1994

HAL is a multi-disciplinary open access archive for the deposit and dissemination of scientific research documents, whether they are published or not. The documents may come from teaching and research institutions in France or abroad, or from public or private research centers.
L'archive ouverte pluridisciplinaire HAL, est destinée au dépôt et à la diffusion de documents scientifiques de niveau recherche, publiés ou non, émanant des établissements d'enseignement et de recherche français ou étrangers, des laboratoires publics ou privés. 


\title{
Numerical and experimental studies of the generation of ultrasound by laser
}

\author{
M. Dubois, F. Enguehard, L. Bertrand, M. Choquet* and J.-P. Monchalin* \\ Ecole Polytechnique de Montréal, Département de Génie Physique, C.P. 6079, Succ. Centre-Ville, \\ Montréal, Québec, Canada, H3C $3 A 7$ \\ * Institut des Matériaux Industriels, Conseil National de Recherches du Canada, 75 boul. Mortagne, Bou- \\ cherville, Québec, Canada, J4B $6 Y 4$
}

\begin{abstract}
We present an analytical 1-D model of the laser generation of ultrasound that takes the optical penetration effect and the time profile of the laser pulse into account. This model leads to simple expressions for the time position and width of the precursor. The results of this model are compared to experimental data. We also present numerical and experimental directivity patterns of samples having various optical penetration depths.
\end{abstract}

\section{INTRODUCTION}

The laser generation of ultrasound has been widely demonstrated as an important tool in the nondestructive evaluation of materials [1,2]. Several approaches were proposed for modeling the thermoelastic generation process [3-5] but very few took the optical penetration effect into account $[6,7]$, studying the laser generation of ultrasound essentially on aluminum samples.

There is now a growing interest in the use of laser-generated ultrasound in non-metals [7-10]. We have developed two models allowing to study the effect of the optical penetration on the laser generation of ultrasound. The first one, an analytical 1-D model, permits to derive expressions for the Full Width at Half Maximum (FWHM) and the time position of the precursor, and the second one, a semi-analytical 3-D model that uses numerical Laplace and 2-D Fourier transformations, allows us to study the effects of virtually any time and surface profiles of the laser excitation on samples presenting an orthotropic symmetry [11]. The results obtained with these two models are compared with those obtained experimentally on samples having various optical penetration depths. In addition, the effect of the optical penetration on the directivity pattern is studied numerically and experimentally.

\section{AN ANALYTICAL 1-D MODEL OF THE PRECURSOR}

\subsection{Assumptions of the model and resolution}

In the case of a uniform laser irradiation, and neglecting the thermal diffusion within the sample, the equation to be solved is:

$$
\frac{1}{v^{2}} \frac{\partial^{2} u(x, t)}{\partial t^{2}}+\alpha \frac{\partial T(x, t)}{\partial x}=\frac{\partial^{2} u(x, t)}{\partial x^{2}} \text { with } T(x, t)=\frac{\beta I_{o}}{\rho C_{p}} e^{-\beta x} \int_{0}^{t} f\left(t^{\prime}\right) d t^{\prime}
$$

where $x$ is the position in the sample of thickness $L, t$ the time, $v$ the longitudinal velocity, $\alpha$ the thermal expansion coefficient and $u(x, t)$ the mechanical displacement field in the $x$ direction. The penetration of the light inside the material induces a temperature elevation field $T(x, t)$, given in (1), where $\beta$ is the optical absorption coefficient, $I_{0}$ the energy per surface unit absorbed by the sample, $\rho$ the density, and $C_{p}$ the specific heat. The function $f(t)$ is the normalized temporal shape of the laser pulse, and is taken equal to:

$$
f(t)=\frac{t}{\tau^{2}} e^{-t / \tau}
$$

since this expression corresponds to the temporal shapes of most Q-switched lasers. 
The initial conditions are $u(x, 0)=0$ and $\dot{u}(x, 0)=0$, where the $\cdot$ indicates a differentiation with respect to time. Regarding the boundary conditions, the two surfaces of the sample (at $x=0$ and $x=L$ ) are assumed mechanically unconstrained.

We are interested in the shape of the precursor, which occurs at times $t \approx L / v$. Thus $\beta v t \approx \beta L>5$. Concerning $\tau$, the value of this parameter is generally much smaller than $L / v$, which means that $t>\tau$. These two remarks allow us to find simplified expressions for the displacement $u(L, t)$ : defining the new variable $y=\beta(v t-L)$ and the parameters $k=\beta v \tau$ and $A=\alpha I_{\alpha} / \rho C_{p}, u(L, t)$ is a function of $y$ only and takes the form:

$$
\begin{array}{ll}
\text { for } \quad-\beta L \leq y \leq 0 & u(y)=A \frac{e^{y}}{(1+k)^{2}} \\
\text { for } \quad 0 \leq y \leq \beta L & u(y)=A\left(\frac{e^{-y}}{(k-1)^{2}}+2 e^{-y / k} \frac{\left(k^{2}-1\right) y-2 k}{\left(k^{2}-1\right)^{2}}\right)
\end{array}
$$

\subsection{Numerical study of the features of the precursor}

To observe the behaviors of the position and value of the maximum of the precursor and of its FWHM, we solved numerically the equations $u^{\prime}\left(y_{\max }\right)=0$ and $u\left(y_{i}\right)=u\left(y_{\max }\right) / 2$. The curves obtained for $y_{\max }$ (the value for which the maximum occurs) and $\mathrm{u}\left(\mathrm{y}_{\max }\right)$ (the amplitude of this maximum) as functions of $\mathrm{k}$ are shown on figure 1 and the curve obtained for the FWHM $\left(\mathrm{y}_{2}-\mathrm{y}_{1}\right)$ is shown on figure 2. To these curves, we superpose data obtained with a semi-analytical 3-D model [11].

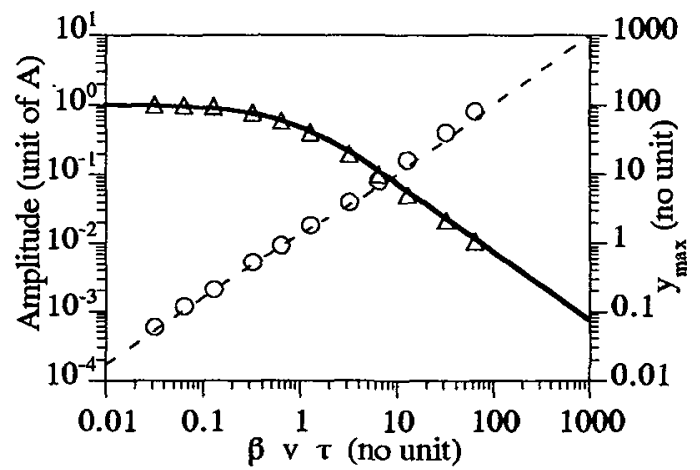

Figure 1 Amplitude and position of the precursor as functions of $k$. The values of the maximum are given in units of $A$. Amplitude curve:

analytical model; $\Delta$ : numerical points. ymax curve: --: analytical model; $\mathrm{O}$ : numerical points.

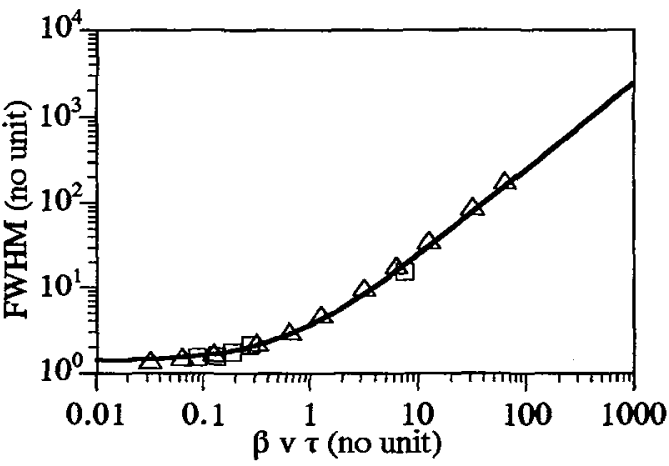

Figure 2 FWHM of the precursor as a function of $k$ : analytical model; $\Delta:$ numerical points; $\square$ : experimental points.

In the case of the FWHM curve, it has been possible to plot experimental points. In the first series of experiments, a pulsed Nd:YAG laser (monomode, beam radius $1 \mathrm{~mm}$, energy up to $100 \mathrm{~mJ}$, pulse halfwidth duration $12 \mathrm{~ns}$ ) was used to generate ultrasound in $3 \mathrm{~mm}$ thick BG-18, BG-39, KG-3 and KG-5 Schott glasses. Their physical parameters were obtained from Schott. Another experiment was performed with a pulsed $\mathrm{CO}_{2}$ laser (multimode, rectangular surface profile $4 \times 8 \mathrm{~mm}^{2}$ in size, energy up to $400 \mathrm{~mJ}$, pulse half-width duration $115 \mathrm{~ns}$ ) and a $2 \mathrm{~mm}$ thick graphite-epoxy composite sample, the optical absorption coefficient of which was measured using the photoacoustic spectroscopy technique [12].

\subsection{Discussion of the results}

Figure 1 shows that $y_{\max } \approx k$ over a large range of $k$ values $(0.01 \leq k \leq 1000)$, which means that $t_{\max } \approx L / v+\tau$. This result is easy to interpret: it corresponds to the time for which the power of the laser pulse reaches its maximum plus the delay of acoustic propagation through the sample.

On figure 2, two asymptotic behaviors appear. For $\mathrm{k}<0.1$, the value of the FWHM can be approximated by $\ln (4)$, which is the exact value when $f(t)$ is a Dirac function: the FWHM of the precursor, $\Delta t_{1 / 2} \approx \ln (4) / \beta v$, is essentially related to the optical absorption. For $k>4$, we have approximately $\Delta y_{1 / 2} \approx$ $2.45 \mathrm{k}$, i.e. $\Delta \mathrm{t}_{1 / 2} \approx 2.45 \tau=$ the FWHM of the laser pulse. In that case, the optical penetration effect is negligible and the. FWHM of the precursor is essentially related to the temporal profile of the laser pulse. In the intermediate domain $0.1 \leq \beta \mathrm{vt} \leq 4$, the effects of optical absorption and of laser pulse duration are 
of the same order of magnitude. A reasonably good correlation between $\Delta t_{1 / 2}$ and the two characteristic times $\tau$ and $1 / \beta v$ can be found:

$$
\Delta \mathrm{t}_{1 / 2}=\frac{\ln (4)}{\beta \mathrm{v}}+2.45 \tau
$$

It is interesting to note that the amplitude curve of figure 1 has a behavior inverse to the one of the FWHM curve, and that the product of the amplitude by the FWHM is nearly constant over the range of k values that we have considered. This result can be associated with a conservation of energy: for the same laser pulse energy and for the same sample, the product of $\Delta t_{1 / 2}$ by the amplitude of the precursor is nearly independent of the laser pulse duration.

We have presented experimental results on samples having different optical penetration depths and with two different excitation sources. The experimental results were always in very good agreement with our very simple 1-D analytical model even when the irradiation experimentally performed could not be considered as uniform. The respect of the condition of uniform irradiation is related to the directivity pattern of the sample. In the case of our Schott glasses, their optical penetration depths made the condition of uniform irradiation not crucial. However, the respect of this condition may be more critical for other materials.

\section{EFFECTS OF THE OPTICAL PENETRATION ON THE DIRECTIVITY PATTERNS}

The thermoelastic generation of ultrasound by laser creates simultaneously surface and bulk (shear and longitudinal) waves [13]. In the case of the bulk waves, the optical penetration has important effects on their directivity patterns and on their relative amplitudes. We present here several directivity patterns calculated with our semi-analytical 3-D model [11] for various optical penetration depths ( $\delta$ ), and an experimental directivity pattern obtained on a BG-18 Schott glass having a $\delta$ of $103 \mu \mathrm{m}$ at the wavelength of our Nd:YAG laser.

\subsection{Results}
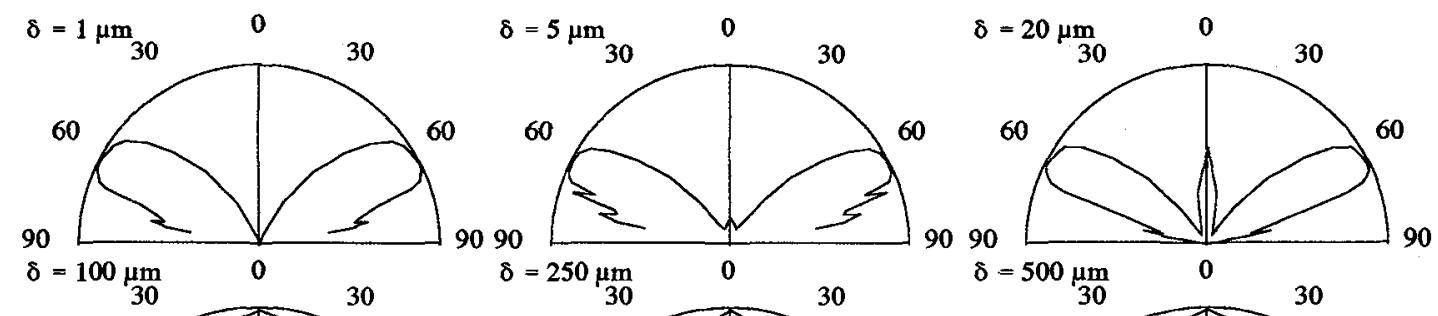

60

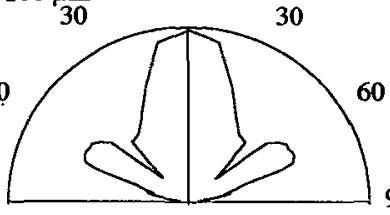

60

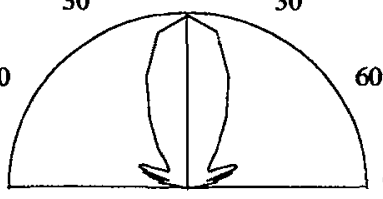

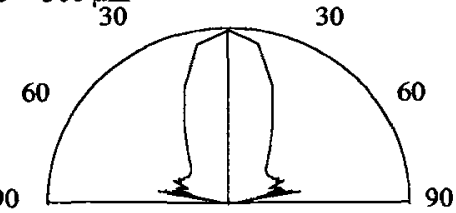

Figure 3 Calculated longitudinal directivity patterns for various optical penetration depths $(\delta)$. The generation spot is a uniform disk $0.5 \mathrm{~mm}$ in diameter.

The experimental displacements were measured using an optical heterodyne probe UltraOptec OP-35 I/O, that can measure both in-plane (in a given direction) and normal displacements [14]. These measurements were performed on a BG-18 Schott glass, on the opposite side to the excitation, at various distances from the epicenter. From this information, it was then easy to calculate the experimental longitudinal and transverse displacements, assuming the generation spot as punctual. The same mathematical manipulations were made to get longitudinaltransverse information from the results of the 3-D model.

In order to be able to compare our directivity patterns to those measured by other authors on semi-cylindrical samples

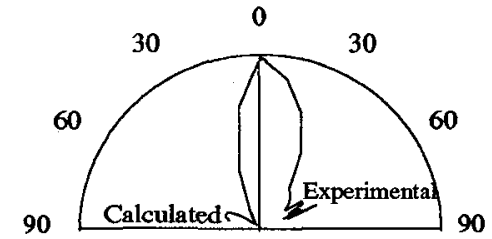

Figure 4 Calculated and experimental longitudinal pattern for the BG-18 Schott glass $(\delta=103 \mu \mathrm{m}$.) The generation spot is a uniform disk $1 \mathrm{~mm}$ in diameter. [15], we must relate our displacements to the distances between measurement and generation. In the case of bulk spherical waves, the far-field attenuation is in $1 / \mathrm{r}[3,16]$, so we multiplied our displacements by 
the distances between measurement and generation. Each value of displacement is weighted to the maximum value of its directivity pattern.

The directivity patterns of the longitudinal wave obtained numerically for various $\delta$ are shown on figure 3. The FWHM of the laser pulse was taken to be 12 ns and a uniform laser beam energy distribution disk $0.5 \mathrm{~mm}$ in diameter was assumed. The other physical parameters of the calculation were those of the BG-18 Schott glass. We do not present the shear directivity patterns since very weak effects of $\delta$ are noticeable on them.

Figure 4 presents the experimental directivity pattern for the BG-18 Schott glass, which has a $\delta$ of $103 \mu \mathrm{m}$. The experimental directivity pattern is confronted to the one calculated with the model and with the experimental energy distribution of the laser beam i.e. a uniform disk $1 \mathrm{~mm}$ in diameter.

\subsection{Discussion on the directivity patterns}

The calculated directivity patterns presented show very well the increase in the proportion of the longitudinal wave propagating normal to the surface of the sample with the increase in $\delta$. A non-negligible optical penetration permits to create buried thermoelastic sources which have similar effects to those of a transparent coating over a sample having a small optical penetration depth [17].

The difference between the calculated directivity pattern for $\delta=100 \mu \mathrm{m}$ (figure 3) and the experimental one arises essentially from the generation spot diameter that is different. The generation spot $1 \mathrm{~mm}$ in diameter produces a larger proportion of longitudinal wave propagating normal to the surface than the one $0.5 \mathrm{~mm}$ in diameter. This is consistent with observations made with piezoelectric transducers which follow the optical diffraction law: their acoustic energy has a lower divergence when the diameter of their active region is larger [16].

\section{CONCLUSION}

Our analytical 1-D model has demonstrated the possibility to relate the absolute value of the optical absorption coefficient to the FWHM of the precursor. It will allow us to measure quantitatively this coefficient by the laser-ultrasonics technique, respecting certain conditions of laser pulse duration and of irradiation. Combined with a photoacoustic experiment allowing the quantitative measurement of the product of the optical absorption coefficient by the square root of the thermal diffusivity [13], we will be able to perform optical and thermal characterizations of materials.

The directivity patterns we have presented demonstrate the importance of the optical penetration on the divergence of the acoustic energy. It is thus important to develop tools allowing to choose easily the generation wavelength in order to be able to obtain the desired directivity (generally normal to the surface). Non-linear optics may offer great possibilities in this area.

\section{REFERENCES}

[1] J.-P. Monchalin, Review of Progress in Quantitative NDE, 12 (1993) 495-506.

[2] C.B. Scruby, L.E. Drain, Laser-Ultrasonics: Techniques and applications, (Adam Hilger, Bristol, UK 1990).

[3] C.B. Scruby, J. Appl. Phys., 51, no.12 (1980) 6210-6212.

[4] P.A. Doyle, J. Phys. D: Appl. Phys., 19, no. 9 (1986) 1613-1623.

[5] F.A. McDonald, Appl. Phys. Lett., 9, no.4 (1989) 230-232.

[6] K.L. Telschow, R.J. Conant, J. Acoust. Soc. Am., 88, no.3 (1990) 1494-1502.

$[7]$ G.S. Taylor, D.A. Hutchins, C. Edwards, S.B. Palmer, Ultrasonics, 28, no.6 (1990) 343-349.

[8] C. Padioleau, P. Bouchard, R. Héon, J.P. Monchalin, F.H. Chang, T.E. Drake, K.I. McRae, Review of Progress in Quantitative NDE, 12 (1993) 1345-1352.

[9] A.D.W. McKie, R.C. Addison Jr., Review of Progress in Quantitative NDE, 12 (1993) 507-516.

[10] C. Corbel, F. Guillois, D. Royer, M. Fink, R. De Mol, IEEE Ultrasonics Symposium Proceedings, 2 (1992) 801-804.

[11] M. Dubois, F. Enguehard, M. Choquet, J.P. Monchalin, L. Bertrand, Review of Progress in Quantitative NDE, 13, in press.

[12] M. Dubois, F. Enguehard, M. Choquet, J.P. Monchalin, L. Bertrand, Opt. Eng. 32, no.9 (1993) 2255-2260.

[13] H.M. Ledbetter, J.C. Moulder, J. Acoust. Soc. Am., 65 no.3 (1979) 840-842.

[14] J.-P. Monchalin, J.-D. Aussel, R. Héon, C. K. Jen, A. Boudreault, R. Bernier, J. Nondestruct. Eval, 8, no.2 (1989) 121-133.

[15] D.A. Hutchins, R.J. Dewhurst, S.B. Palmer, J. Acoust. Soc. Am., 70, no.5 (1981) 1362-1369.

[16] J.Krautkrämer, H.Krautkrämer, Ultrasonic Testing of Materials, (Springer-Verlag, Berlin, 1990).

[17] D.A. Hutchins, R.J. Dewhurst, S.B. Palmer, Ultrasonics, 19, no.3 (1981) 103-108. 